Article

\title{
Tall-Building Projects Sustainability Indicator (TPSI): A New Design and Environmental Assessment Tool for Tall Buildings
}

\section{Binh K. Nguyen and Hasim Altan *}

School of Architecture, The University of Sheffield, The Arts Tower, Western Bank Sheffield, S10 2TN, UK; E-Mail: binhshef1985@gmail.com

* Author to whom correspondence should be addressed; E-Mail: h.altan@sheffield.ac.uk;

Tel.: +44-0-114-222-0375; Fax: +44-0-114-222-0315.

Received: 13 February 2012; in revised form: 21 March 2012 / Accepted: 9 April 2012 /

Published: 16 April 2012

\begin{abstract}
The paper presents the features of Tall-building Projects Sustainability Indicator (TPSI) - a "Sustainability Rating System" that specializes in tall-building projects. The system comprises two components; the "Technical Manual" in the form of a booklet and the "Calculator" in the form of an Excel tool. It can be used as a "design tool" and/or as a "checklist" to compare and to improve the sustainable performance of tall-building design schemes. At the same time, the system can be used to evaluate the sustainability of existing tall-building projects. The first version of the TPSI rating system (TPSI 2012 Version) was released as an online tool (GreenLight) and thoroughly examined and validated by multiple parties.
\end{abstract}

Keywords: tall building; high-rise project; building sustainability; rating system; assessment method; environmental rating

\section{Introduction}

The market place for the design and construction of high performance buildings is dynamic and ever evolving. Professionals throughout the building industry use assessment rating systems to evaluate and differentiate their products or designs [1]. After more than 20 years of development, sustainable rating systems have become invaluable as sustainable development is now the global trend. 
Among the numerous developed rating tools, tall-building evaluation is a neglected area [2]. As there is as yet no specialized rating system for tall-buildings, most of the existing systems are used for all types of projects, which causes inappropriate and inaccurate decisions [2]. This research aims to improve the quality of tall-buildings' sustainability assessment activities by developing a new sustainability rating system named "TPSI-Tall-building Projects Sustainability Indicator". It has also established a set of standards for sustainable tall-buildings, which can be utilized for many purposes.

\section{Gaps in Existing Rating Systems}

\subsection{The Confusion between "Green" and "Sustainable"}

Environmentally progressive building practice is currently described using a variety of different tags: "green design", "ecological design" or "sustainable design". Although discussions regarding the most appropriate terminology describing environmentally progressive buildings can be deteriorated to meaningless semantics, the distinction between the notions of "green" and "sustainable" is critical in structuring environmental assessment methods [3]. These fundamental differences, surprisingly, often are neglected in existing rating systems. In original rating systems such as BREEAM (UK) or LEED (USA), these differences were quite well defined. In later generations of ratings systems (i.e., the systems that have been developed based on one or several original ones), the line between "green" and "sustainable" gradually faded away.

\subsection{The Confusion between "Quantitative" and "Qualitative” Criteria}

Assessing "building sustainability" performance, which is largely an issue of energy and mass flows, must be described in quantitative terms. On the other hand, the wider range of performance issues necessary within an assessment of "green" currently cannot avoid using more qualitative metrics to evaluate a building comprehensively [3]. A good combination of quantitative and qualitative criteria will ensure a thorough and sufficient evaluation. In contrast, any confusion will lead to inadequate structure of assessment criteria as a result of the ineffectiveness of the assessment.

\subsection{The Confusion between "Assessment" and "Design"}

This common confusion causes troubles for both the system's developer (when building up assessment criteria) and users (when choosing among versions and using them to evaluate their buildings). For instance, although conceived as assessment tools to evaluate a completed building design, some existing rating systems such as BREEAM (UK), LEED (USA), GBTool (International), CASBEE, HK-BEAM (Hong Kong), etc. are commonly used as design tools. Whether or not a single system can function equally effectively as an assessment and as a design tool, is an important question. If the answer is "yes", then what would be necessary in an assessment tool to enable it to be useful in design? The answer lies in the structure of the assessment framework and with the skill and enterprise of the users [4]. 


\subsection{Specialization}

Tall-buildings have very distinctive technical and architectural features in comparison to other types of building. Low and medium-rise buildings, whether residential, commercial centers, schools or offices, all have similar construction, operation and demolition procedures. Tall-buildings, on the other hand, have totally different procedures and there is a need for specialized assessment criteria to be adequately evaluated. Existing rating systems which are commonly used to assess tall-buildings, such as BREEAM Office, CASBEE New Construction, GREEN STAR Office Design or HK-BEAM New Buildings, seriously lack dedicated assessment criteria for tall-buildings. Specifically, in the following areas: Construction technologies and procedures, foundation construction, building services, social and economic aspects, material utilization, energy utilization, earthquake management, living quality inside tall-buildings, etc. [2].

\subsection{Bulkiness}

The systems of assessment criteria of existing tools such as BREEAM, LEED, CASBEE, GREEN STAR, etc. are often very rich in technical contents. Normally an individual architect cannot even finish the assessment process on his own because of lacking specialized technical knowledge. It often takes several days or even several weeks to finish an assessment (data collection, data input, document gathering, etc.) [2]. This then becomes a major issue in the design stage, where these tools are likely to be used again and again to test different design solutions.

\section{TPSI Rating System}

\subsection{The Visions}

The visions for TPSI rating scheme encompass the following main points:

- TPSI is strictly a "Design" tool. Its interface, assessment method, result presentation and other features are dedicated to improving sustainable performance at the early stages of projects.

- TPSI is specialized for high-rise buildings only (i.e., buildings of more than 20 stories). This means TPSI has a unique and dedicated system of assessment criteria and assessment methods, which increases the accuracy of the evaluations over other rating schemes.

- TPSI is designed to be a user friendly, concise and handy tool. Assessment criteria are simplified and presented in an easy-to-understand way. The data inputting process will be speeded up. Technical inputs that are difficult to retrieve will be limited. TPSI is able to produce quick and sufficient evaluations, which makes it most suitable at the design stage when comparing different design schemes.

- TPSI's assessment criteria system is a harmony of Quantitative and Qualitative criteria.

- Assessment results are presented in a well-defined and easy-to-communicate manner.

- Results are in presented in the form of ratings, charts and graphs, enhancing the comparability of the outputs.

- Setting a higher standard for sustainable tall-buildings/projects. 


\subsection{The Structure of TPSI}

The TPSI system (2012 Version) comprises two components: The "Manual" (in the form of a booklet), and The "Calculator" (in the form of a Microsoft Excel tool). Users will claim "credits" for their tall building project by demonstrating compliance with the assessment criteria that are detailed in the "Manual". The achieved credits will be inputted into the "Calculator" accordingly. The "Calculator" will then produce assessment results in form of ratings (percentage), charts, graphs, comments and recommendations on how to improve the design, etc.

\subsection{Scope of Assessment}

\subsubsection{Types of Buildings that can be Assessed by TPSI}

TPSI is specialized for buildings of more than 20 stories or more than 60 meters in height, regardless of their functions. There are many reasons for this choice of threshold, but the most important one is: 20 stories is the threshold where all the design, planning, construction, maintenance and deconstruction of a building change dramatically. This threshold was actually set a long time ago by the renowned architect/engineer Fazlur Khan in 1969 [5]. Khan classified structural systems for tall buildings relating to their height with considerations for efficiency in his "Heights for Structural Systems" diagrams (see Figure 1). According to Khan's work, the 20 stories is the efficiency limit (in term of both structural and economic aspects) of concrete framed structures. He also further suggested that steel structures should not be less than 20 stories to be most sufficient.

Figure 1. Classification of tall building structures by Fazlur Khan (top: Steel; bottom: Concrete).

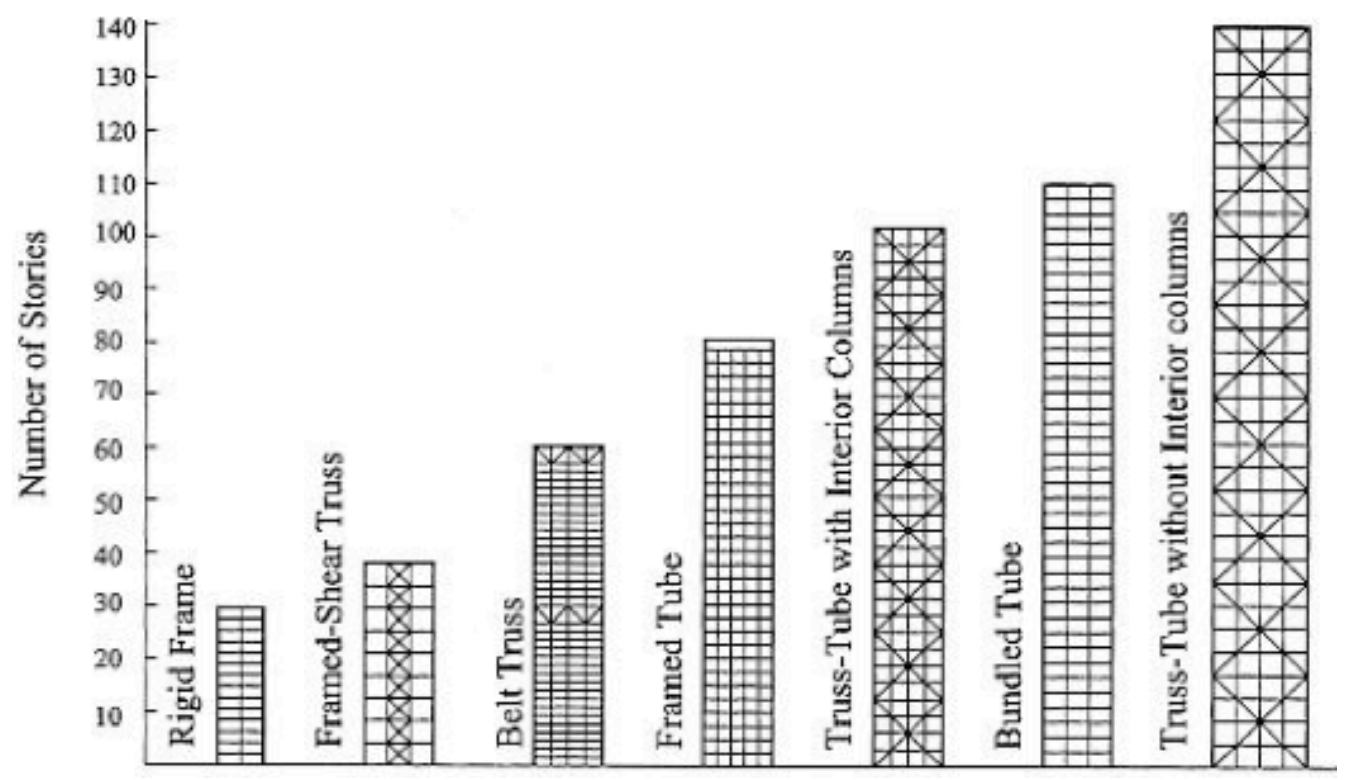


Figure 1. Cont.

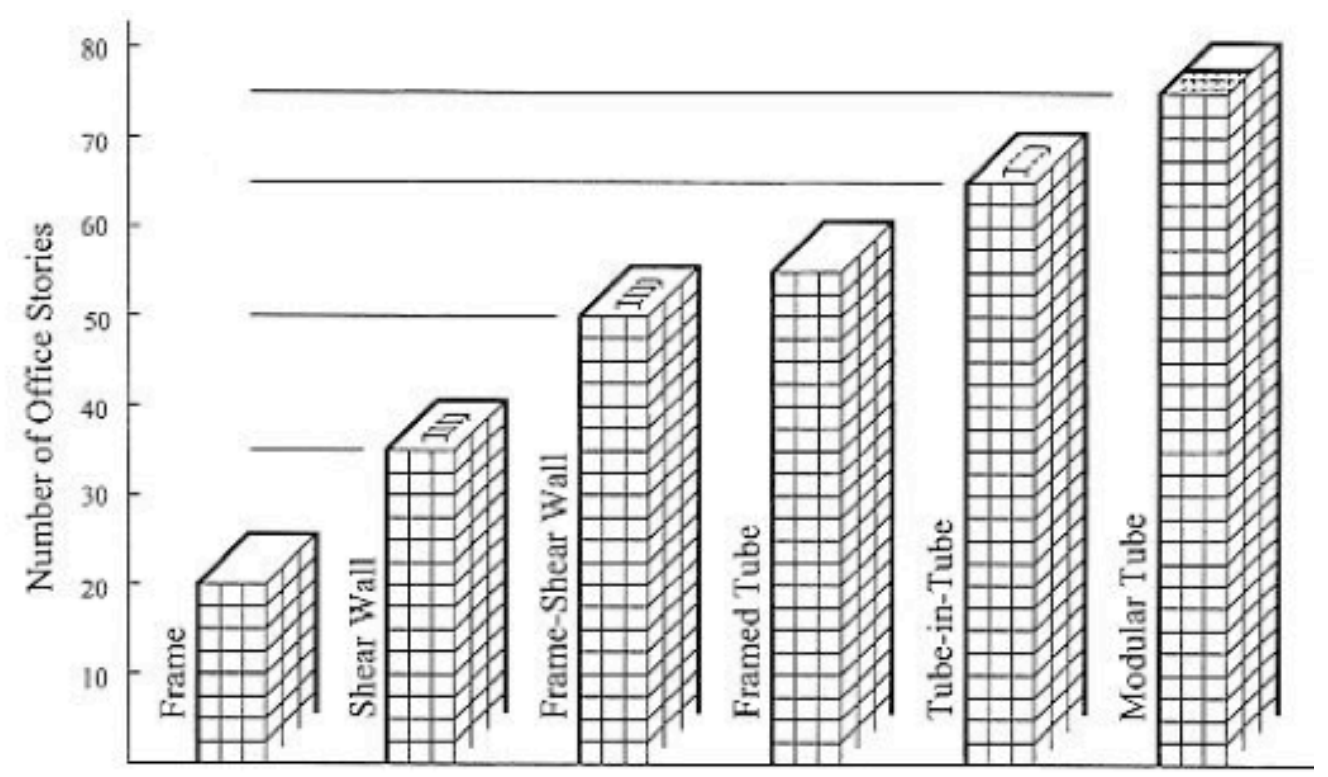

This 20 stories threshold was again confirmed by Ali and Moon in 2007. In their very thorough research [6], they have established that the Efficient Height Limit of the traditional concrete interior-rigid-frame structure is 20 stories. When surpassing this threshold, the elements affecting height, such as lateral forces, shear lag, structure self-weight, elevator and other types of space allocations, economic, construction technologies, maintenance requirements, etc. necessitate further considerations of structure, in particular, and design strategies in general.

Please note that there are many theories and definitions for tall-buildings. This 20 stories threshold is chosen because it is most suitable for TPSI only; it is not an attempt to set a new definition that can be applied everywhere.

\subsubsection{Stages of Assessment}

TPSI is most suitable to be used during the following stages:

- Design Stage: a Design Stage Assessment represents the performance of the tall-building prior to the beginning of operations on site. To complete an assessment at this stage, the design must be advanced to the point where the relevant information is available to enable the user to demonstrate, in a robust manner, the building's performance against the reporting and evidential criteria of the TPSI Technical Manual. A design stage assessment cannot be verified by a third party due to the lack of actual documented evidences.

- Post-Construction Stage: The Post-Construction Assessment represents the final "as built" performance and TPSI rating. A post-construction assessment can be verified by a third party if all documented evidences are available.

\subsubsection{Types of Projects that can be Assessed by TPSI}

A TPSI assessment can be carried out at the above stages for the following types of tall-building projects: 
- Whole new tall-building;

- Major refurbishments of existing tall-buildings;

- New-build extensions to existing tall-buildings;

- A combination of new-build and existing building refurbishment;

- New-build or refurbishments which are part of a larger mixed use building;

- Existing building fit-out.

\subsection{Assessment Criteria System-The "Manual"}

TPSI contains 119 default issues divided into eight categories, covering all aspects of sustainable tall building development. These eight categories are further divided into two main groups. There is one additional category that allows users to earn extra credits for innovative features of their project or for exceeding the design standard stated in the "Manual". A certain number of "credits" are available for each issue. Table 1 summarizes TPSI's assessment criteria system and corresponding credits.

Table 1. TPSI's system of assessment criteria.

\begin{tabular}{|c|c|c|c|}
\hline B-BUILDING PERFORMANCE & Credits & E-ENVIRONMENTAL PERFORMANCE & Credits \\
\hline B1. Project Management (PM) & 29 & E1. Resources Consumption (RC) & 44 \\
\hline PM1. Basic Principles & 3 & RC1. Land Use \& Re-use & 2 \\
\hline PM2. Environmental Management & 5 & RC2. Land Use Efficiency & 1 \\
\hline PM3. Site Investigation & 3 & RC3. On-site Resources & 1 \\
\hline PM4. Whole-life Approach & 2 & RC4. Annual Water Consumption & 4 \\
\hline PM5. Site Design Appraisal & 1 & RC5. Monitoring and Control & 2 \\
\hline PM6. Choice of Construction Process & 1 & RC6. Water Efficient Irrigation & 1 \\
\hline PM7. Construction Site impacts & 4 & RC7. Water Harvesting and Recycling & 3 \\
\hline PM8. Construction Safety & 2 & RC8. Water Efficient Facilities \& Appliances & 1 \\
\hline PM9. Contractual \& Procurement & 3 & RC9. Innovative Wastewater Technologies & 1 \\
\hline PM10. Commissioning & 2 & RC-P1. Basic Energy Performance & Required \\
\hline PM11. Operation Management Plan & 1 & RC10. Energy Use Reduction & 18 \\
\hline PM12. Building User Guide & 1 & RC11. Energy Use in Car Parks \& Public Areas & 2 \\
\hline PM13. Demolition Management Plan & 1 & RC12. Low or Zero Carbon Technologies & 4 \\
\hline B2. Indoor Environmental Quality (IEQ) & 35 & RC13. Clothes Drying Facilities & 1 \\
\hline IEQ-P1. Minimum Ventilation & Required & RC14. Energy Efficient Appliances & 1 \\
\hline IEQ1. Water Quality & 1 & RC15. Metering and Monitoring & 2 \\
\hline IEQ2. Plumbing and Drainage & 1 & E2. Material Aspects (MA) & 20 \\
\hline IEQ3. Biological Contamination & 1 & MA-P1. Timber Used for Temporary Works & Required \\
\hline IEQ4. Waste Disposal Facilities & 1 & MA1. Materials Specification & 8 \\
\hline IEQ5. ETS control & 1 & MA2. Certified Wood & 1 \\
\hline IEQ6. Construction IAQ Management & 2 & MA3. Rapidly Renewable Materials & 2 \\
\hline IEQ7. Outdoor Sources of Air Pollution & 2 & MA4. Recycled Content & 2 \\
\hline IEQ8. Indoor Sources of Air Pollution & 3 & MA5. Regional Materials & 2 \\
\hline IEQ9. IAQ in Car Parks & 1 & MA6. Building Reuse & 1 \\
\hline IEQ10. Increased Ventilation & 1 & MA7. Modular and Standardized Design & 1 \\
\hline IEQ11. Natural Ventilation & 1 & MA8. Prefabrication & 1 \\
\hline
\end{tabular}


Table 1. Cont.

\begin{tabular}{|c|c|c|c|}
\hline B-BUILDING PERFORMANCE & Credits & E-ENVIRONMENTAL PERFORMANCE & Credits \\
\hline IEQ12. Localized Ventilation & 2 & MA9. Efficient Structure Design & 1 \\
\hline IEQ13. Ventilation in Common Areas & 2 & MA10. Design for Robustness & 1 \\
\hline IEQ14. Thermal Comfort Design & 2 & E3. Environmental Loading (EL) & 32 \\
\hline IEQ15. Thermal Zoning & 1 & EL1. Construction/Demolition Waste & 2 \\
\hline IEQ16. Natural Lighting \& Glare & 2 & EL2. Recycled and Secondary Aggregates & 1 \\
\hline IEQ17. Interior Lighting 1 & 2 & EL3. Waste Recycle Facilities & 1 \\
\hline IEQ18. Interior Lighting 2 & 1 & EL4. Compactor/Baler & 1 \\
\hline IEQ19. High Frequency Lighting & 1 & EL5. Compositing & 1 \\
\hline IEQ20. Lighting Zones and Control & 1 & EL6. Land Pollution & 1 \\
\hline IEQ21. View Out & 1 & EL7. Refrigerant Use and Leakage & 3 \\
\hline IEQ22. Room Acoustics & 1 & EL8. NOX Emissions & 3 \\
\hline IEQ23. Noise Isolation & 0 & EL9. Water Pollution & 1 \\
\hline IEQ24. Background Noise & 1 & EL10. Flood Risk & 3 \\
\hline IEQ25. Indoor Vibration & 1 & EL11. Noise Pollution & 1 \\
\hline IEQ26. Private Open Space & 1 & EL12. Light Pollution & 1 \\
\hline IEQ27. Visual Privacy & 1 & EL13. Overshadowing and Views & 1 \\
\hline B3. Building Services (BS) & 17 & EL14. Protection of Ecological Value & 1 \\
\hline BS1. Access for Persons with Disability & 1 & EL15. Mitigation of Ecological Impacts & 2 \\
\hline BS2. Amenity Features & 1 & EL16. Enhancement of Ecological Value & 3 \\
\hline BS3. Water Supply \& Drainage System & 1 & EL17. Long-term Impact on Bio-diversity & 2 \\
\hline BS4. Electrical Equipment & 1 & EL18. Surrounding Microclimate & 4 \\
\hline BS5. HVAC System & 1 & E4. Social \& Economic Aspects (SE) & 16 \\
\hline BS6. Communications \& IT Equipment & 1 & SE1. Public Transport & 3 \\
\hline BS7. Service Life of Components & 2 & SE2. Pedestrian and cyclist & 3 \\
\hline BS8. Maintenance of Core Functions & 1 & SE3. Maximum Car Parking Capacity & 1 \\
\hline BS9. Security & 1 & SE4. Travel Plan & 1 \\
\hline BS10. Fire Safety and Evacuation & 3 & SE5. Neighborhood Amenities & 1 \\
\hline BS11. Lifts & 1 & SE6. Local Character & 1 \\
\hline BS12. Escalator \& Walkways & 1 & SE7. Historic Environment & 1 \\
\hline BS13. Earthquake Resistance & 2 & SE8. Life Cycle Cost and Payback Time & 2 \\
\hline B4. Design Features (DF) & 12 & SE9. Affordability of Rental/Cost Levels & 1 \\
\hline DF1. Energy Efficient Building Layout & 2 & SE10. Support of Local Economy & 1 \\
\hline DF2. Provision of Space & 1 & SE11. Mixed-use Development & 1 \\
\hline DF3. Maintenance Management & 2 & & \\
\hline DF4. Spatial Flexibility & 3 & Innovations (IN) & 16 \\
\hline DF5. Spatial Margin & 2 & IN1. Innovative Strategies \& Technologies & 5 \\
\hline DF6. Floor Load Margin & 1 & IN2. Exemplary Performance & 11 \\
\hline DF7. Adaptability of Facilities & 1 & & \\
\hline
\end{tabular}

\subsection{Assessment Methodology}

There are two main elements that can determine a Tall-building's rating:

- The Total Score; and

- The Balance Factor (or TPSI Factor). 


\subsubsection{The Total Score}

The TPSI Total Score is calculated as follows:

- For each TPSI section, the users must determine the number of credits achieved in accordance with TPSI's assessment criteria (detailed in the "Manual"). The percentage of the credits achieved is calculated for each TPSI section.

- A weighting system is applied to all Section Scores to reflect the importance of each category.

- The percentage of credits achieved is then multiplied by the corresponding TPSI Sections' weighting factor. This gives the "Section Score".

- Section Scores and the Innovation Section score are then added together to give the Total Score.

\subsubsection{The TPSI Factor}

The TPSI Factor is calculated as follow:

- As shown in Table 1, the assessment criteria are grouped into two main categories: the "B Group" which stands for "Building Performance", and the "E Group" which stands for "Environmental Performance". The main idea behind this is to assess the balance between the building's performance and the loadings to the environment in order to achieve that performance level (see Figure 2).

Figure 2. The mechanism behind TPSI Factor.

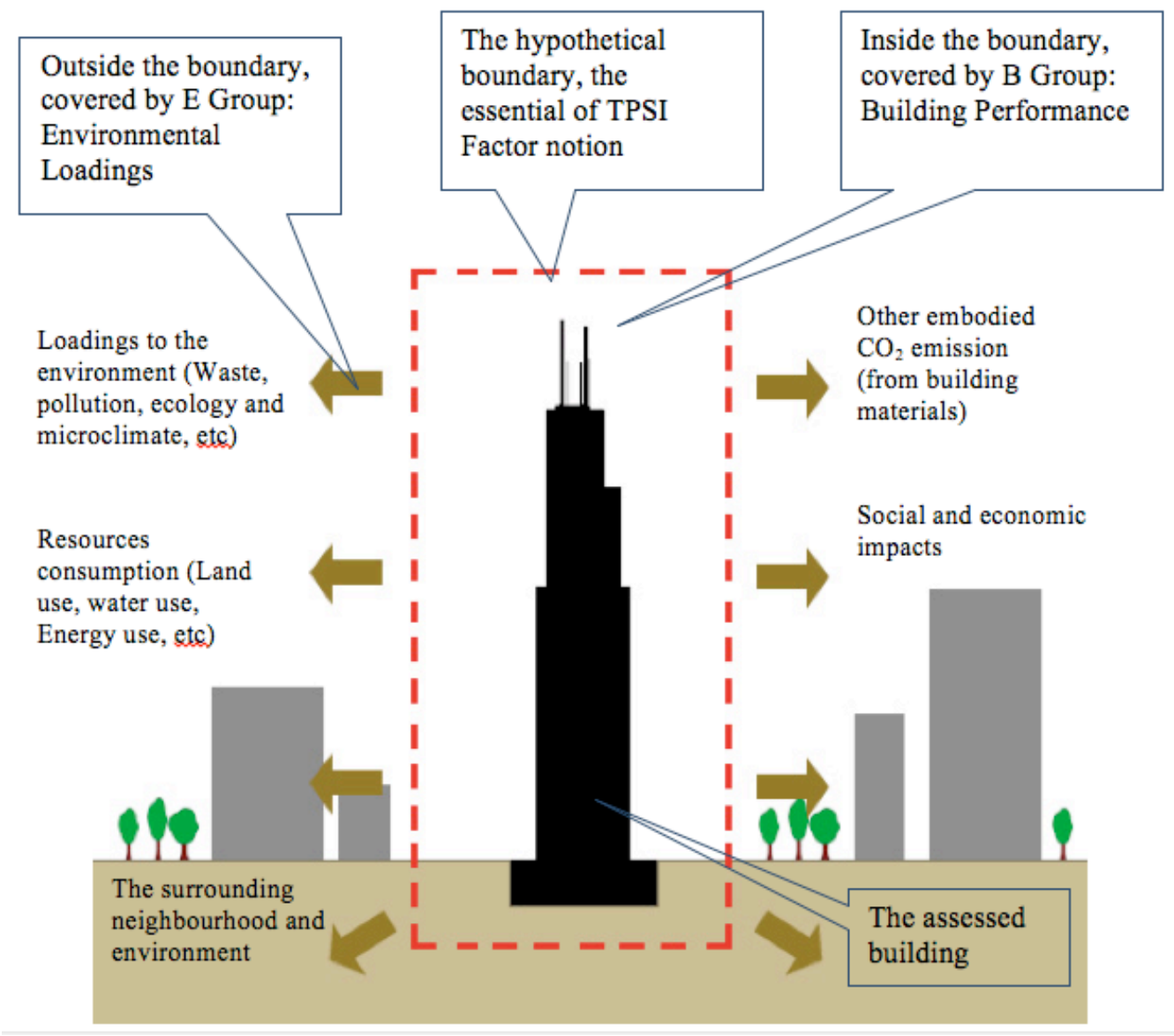


- The percentage of the credits achieved is calculated for both groups. These are expressed as the Total Score for B and the Total Score for E.

- The TPSI factor is defined as B/EL: EL (Environmental Loadings) $=100 \%$-Total Score for E.

- B and EL are plotted on a graph, with EL on the X axis and B on the Y axis. The higher the B value and the lower the EL value, the steeper the gradient and the more sustainable the building is (see Figure 3).

Figure 3. A sample calculation of TPSI Factor.

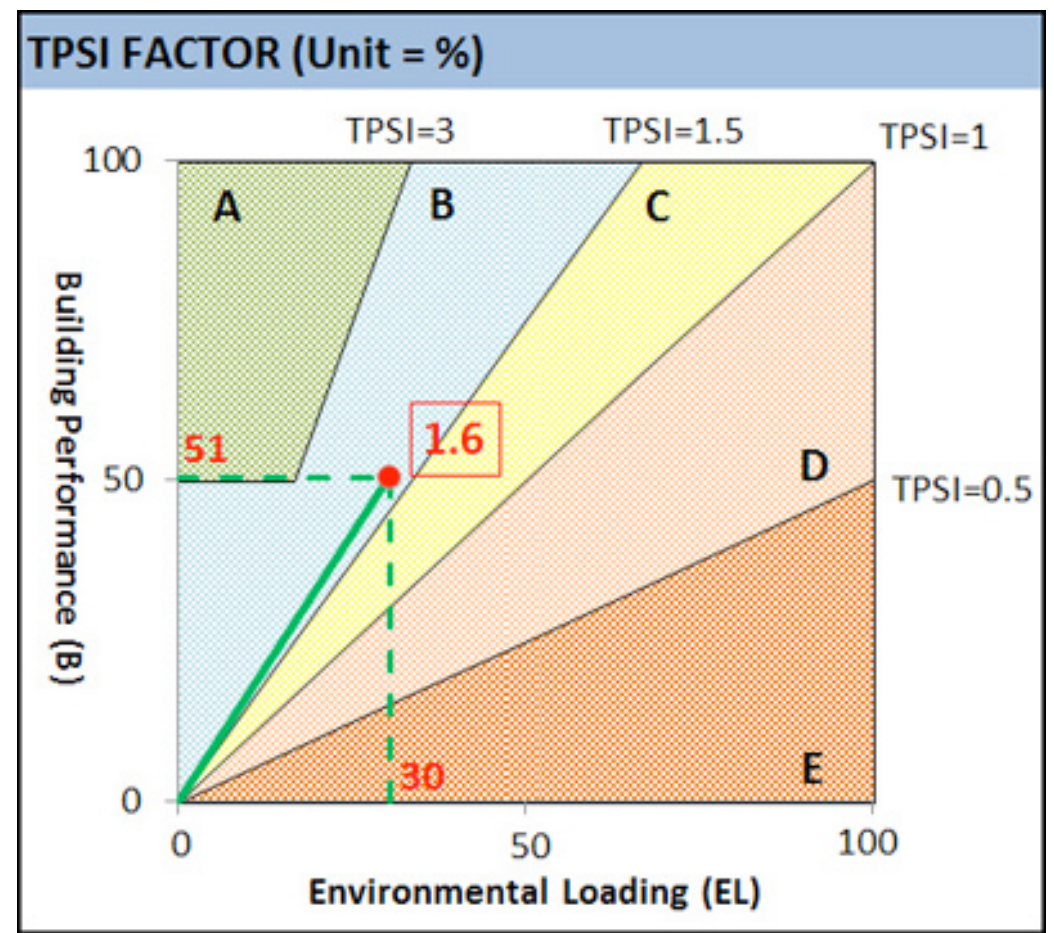

\subsubsection{TPSI Rating}

TPSI introduces a labeling classification of five levels to rate the sustainable performance of a tall-building project (A, B, C, D, E-with A being optimal) (see Table 2). The users do not have to do any of these calculations themselves, including the calculations related to special issues (i.e., issues that can be scoped out or can be achieved by default, prerequisite issues, etc.). They only have to claim the credits using the TPSI Calculator. All the calculations and results are automatically generated.

Table 2. TPSI ranking.

\begin{tabular}{cccc}
\hline Rank & Total Score & TPSI Factor & Comments \\
\hline E & $<25 \%$ & $<0.5$ & Unclassified \\
D & $\geq 35 \%$ & $\geq 0.5$ & Pass \\
C & $\geq 50 \%$ & $\geq 1$ & Good \\
B & $\geq 75 \%$ & $\geq 1.5$ & Excellent \\
A & $\geq 85 \%$ & $\geq 3.5$ & Outstanding \\
\hline
\end{tabular}




\subsection{Assessment Process-The "Calculator"}

The "Calculator" incorporates all assessment mechanisms into an intricately coded Excel tool. All the users have to do is to put in the project's information and claim the credits achieved. The Calculator will automatically calculate the Section Scores, apply the weighting, calculate the Total Score and TPSI Factor, produce graphs, charts, design recommendations, etc. TPSI Calculator is password-protected so users cannot change the core contents of the software; they can only input the project information and claim credits where awarded. TPSI Calculator 2012 Version contains 13 tabs in total (see Table 3).

Table 3. Summary of TPSI Calculator's tabs.

\begin{tabular}{|c|c|c|}
\hline Tab Name & Description & Note \\
\hline INTRODUCTION & $\begin{array}{l}\text { - What is TPSI? } \\
\text { - What does TPSI do? } \\
\text { - Conditions for Use } \\
\text { - Credits }\end{array}$ & \\
\hline HOW TO USE & $\begin{array}{l}\text { - Step-by-step instructions } \\
\text { - Introduction to Result Presentation } \\
\text { - What do TPSI rankings mean? }\end{array}$ & \\
\hline PROJECT INFO. & Project Information & Input tab \\
\hline $\begin{array}{l}\text { B1. PM } \\
\text { B2. IEQ } \\
\text { B3. BS } \\
\text { B4. DF }\end{array}$ & $\begin{array}{l}\text { Assessment criteria according to } 4 \text { categories } \\
\text { of Group B-Building Performance }\end{array}$ & \multirow{3}{*}{ Assessment tabs } \\
\hline $\begin{array}{l}\text { E1. RC } \\
\text { E2. MA } \\
\text { E3. EL } \\
\text { E4. SE }\end{array}$ & $\begin{array}{l}\text { Assessment criteria according to } 4 \text { categories } \\
\text { of Group E-Environmental Performance }\end{array}$ & \\
\hline $\mathrm{IN}$ & $\begin{array}{l}\text { Assessment criteria according to } \\
\text { "Innovation" category }\end{array}$ & \\
\hline RESULT & Result Presentation & \\
\hline
\end{tabular}

\subsubsection{How to Use}

The simplified steps to assess a tall-building project using TPSI are as follow:

- Step 1: Enter the required project details into the "Project Info" tab. Refer to the notes at the end of the "Project Info" tab for instructions on inputting related information.

- Step 2: Switch to the next tab ("B1. PM"). Input the archived credits for each issue by selecting from the drop-down lists. Summarize the design considerations for the related category in the box at the end of the tab.

- Step 3: During the assessment process, refer to the TPSI Technical Manual 2012 Version for further guidance on assessment criteria/procedures and required evidence in order to score each corresponding issue.

- Step 4: For some particular issues, there are options to scope out some or all available credits. Select the appropriate available credits from the drop-down list and then input achieved credits 
as in Step 2. Refer to the TPSI Technical Manual 2012 Version for requirements needed to scope out available credits.

- Step 5: Repeat Steps 2-4 for all remaining tabs (from "B2. IEQ" to "IN").

- Step 6: Switch to the last tab ("Result") for assessment results.

\subsection{2. "Project Info" Tab and the Dynamic Weighting System}

A weighting system is applied to all Category Scores to reflect the importance of each category. The default weighting factors applied to each assessment criteria category is as shown in Table 4. The default weighting factors were determined by consulting the criteria systems of some popular existing rating systems such as BREEAM, LEED, CASBEE, Green Star, HK-BEAM, etc. However, this weighting system is not fixed, it can automatically change based on the project's characteristics.

Table 4. Default weighting factors.

\begin{tabular}{lccccccccc}
\hline Categories & B1 & B2 & B3 & B4 & E1 & E2 & E3 & E4 & IN \\
\hline Weighting factors & $11 \%$ & $14 \%$ & $9 \%$ & $8 \%$ & $18 \%$ & $8 \%$ & $15 \%$ & $9 \%$ & $8 \%$ \\
\hline
\end{tabular}

It is critical to understand that the value of weighting factors, important as it is, should not be central to an environmental rating tool. Assigning weighting factor to reflect the importance of a certain aspect toward overall sustainability is indeed a very good strategy. However, even with internationally renowned systems such as BREEAM or LEED, the allocation of credits (another expression of weighting factors), is always an internal process and cannot be correct everywhere. A single set of weighting factors cannot represent the interrelation of sustainability aspects of all countries and regions worldwide. Trying to establish an "ideal" set of weighting factors, is therefore a rather pointless endeavor. In fact, it is more reasonable to allow the alteration of weighting factors according to different contexts (the Dynamic Weighting System). Green Star has adopted this strategy successfully: employing different weighting factors for different states of Australia, so the system can be used in various regions with higher accuracy.

By applying a dynamic weighting system, TPSI can adapt itself to different contexts and different types of tall-building projects. Changing the weighting factor of each category means changing its contribution towards the overall score and also reflecting its varied importance in different contexts, and therefore it produces a more accurate evaluation. This is a highly important advantage of TPSI over other existing rating systems.

Figure 4 shows some screenshots of the "Project Info" tab. This is where users fill in information about their tall-building project (project name, location, completion date, construction and gross floor area, number of floors, height, occupancy, climate zone, building type, special technical systems, structure types, etc.). All these data will be used to calculate the weighting factor for each criteria category. At the moment, TPSI 2012 Version's weighting factors are dependent on three factors:

- Climate zones (Cold-polar, Hot-humid, Hot-dry or Temperate);

- Project's social context (City-centers or Rural Areas);

- Building types (Mixed-use, Office, Commercial, Residential, Hotel, Health-care or Education). 
Figure 4. "Project Info" tab-screenshots.
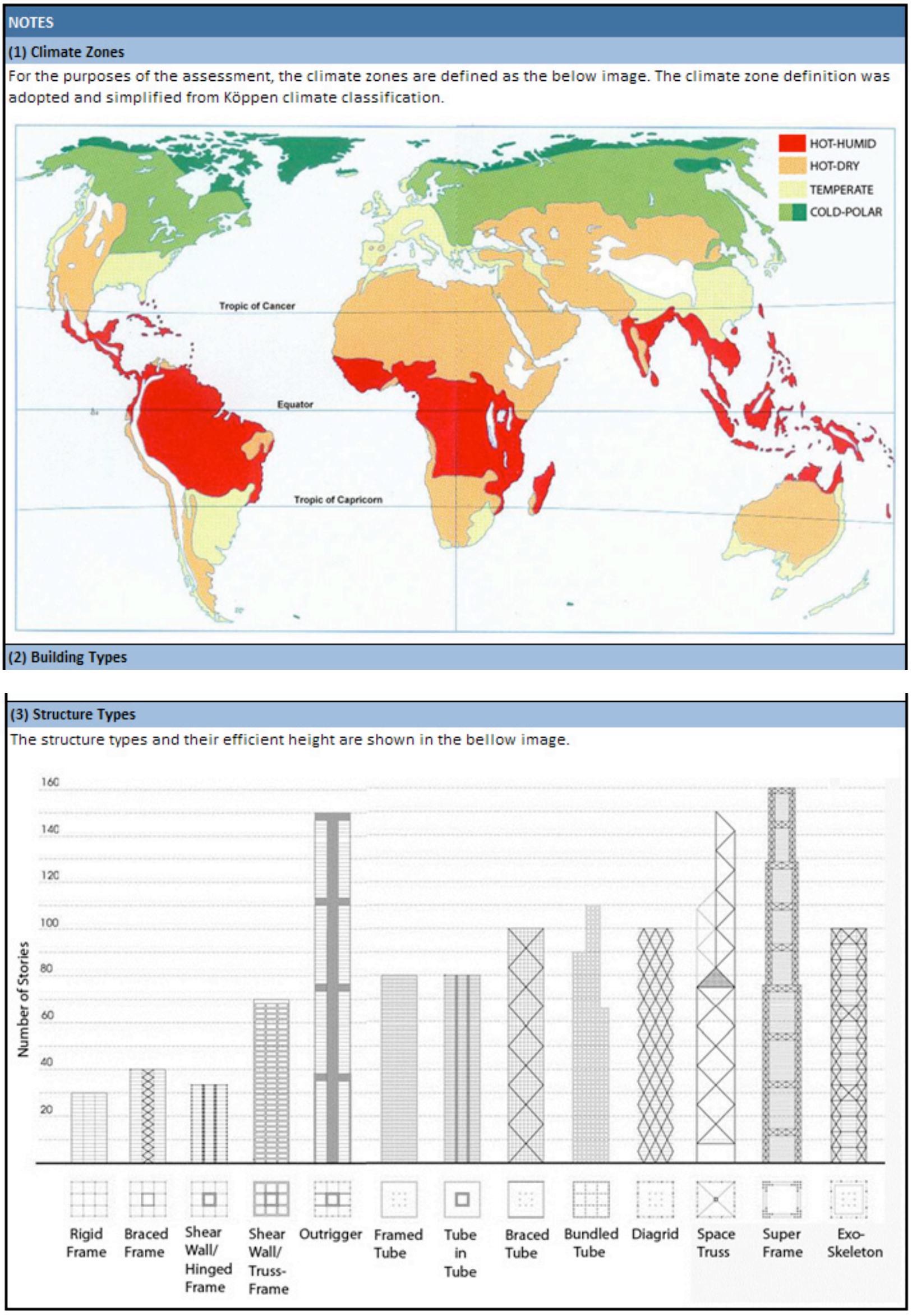


\subsubsection{Assessment Tabs}

Users will claim credits for their project using nine assessment tabs, according to eight main categories and an "Innovation" category. These nine tabs are similar in terms of layout. Figure 5 shows a sample screenshot of one of the assessment tabs. Users do not have to finish off an "Assessment" tab before switching to another one. They can freely examine and work with TPSI issues in the order provided or according to their own priorities, thus gradually improving their project's aspects as it is being developed. Some issues allow the option out of cancellation in case they are not appropriate to the project. Section Scores are automatically updated and design recommendations to improve project's performance are generated.

Figure 5. Sample screenshot of an Assessment tab.

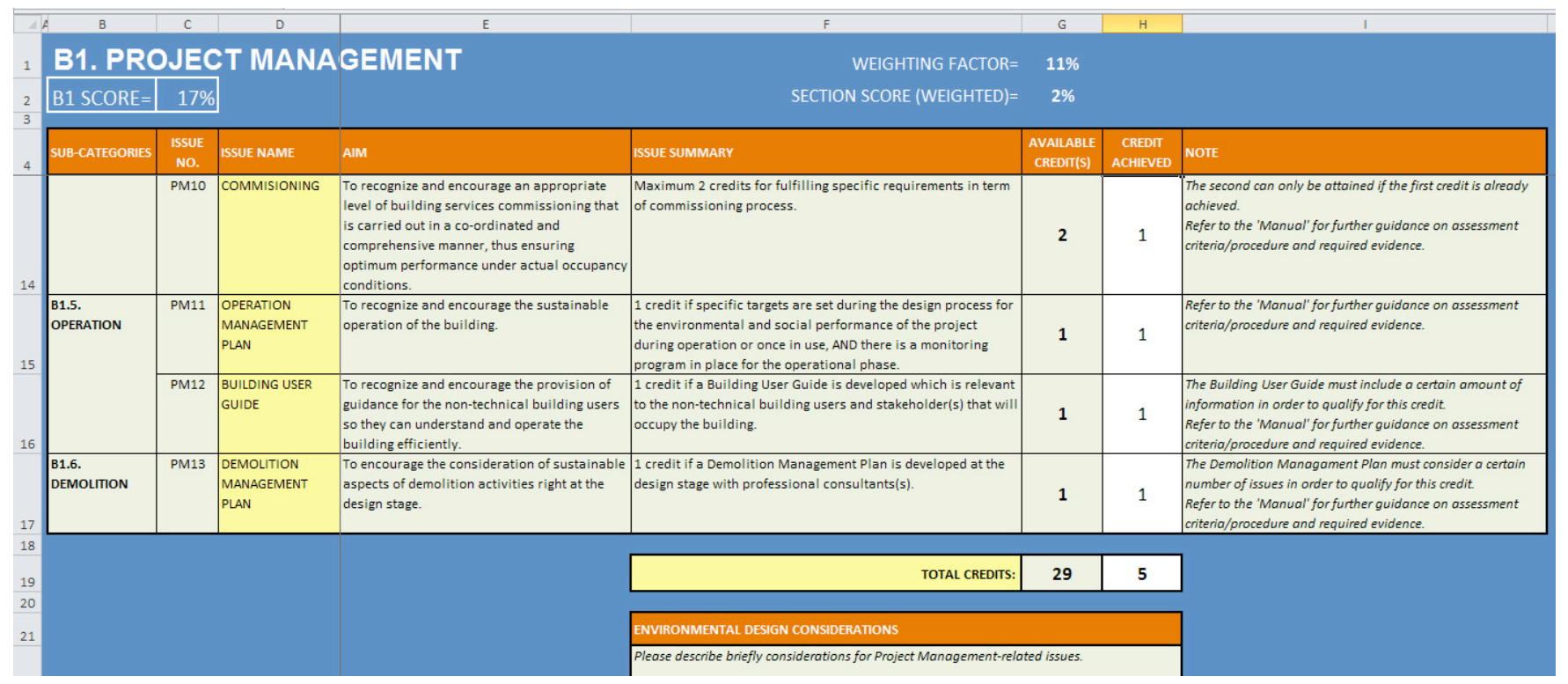

\subsection{4. "Result" Tab}

The "Result" Tab presents the assessments, evaluations, charts, graphs, design recommendations, summaries, overall ranking and other outcomes of the evaluation process. Figure 6 shows an example of some main charts, graphs and ranking available in the "Result" tab.

\section{TPSI in Practice}

\subsection{The Trial Period}

The Trial Period, which commenced in October 2010, was divided into two main phases: the Self-testing Phase and the External-testing phase (or the Interview Process). During the Self-testing Phase, with the acknowledgement and support of Christopher Jones Studentship (University of Sheffield, School of Architecture), technical issues of TPSI were solved; and the first complete version of TPSI was ready to use. In the External-testing Phase, various aspects of TPSI were scrutinized and evaluated by multiple parties; and, based on the participants' feedbacks, TPSI was continuously perfected. 
Figure 6. "Result" tab-screenshot.

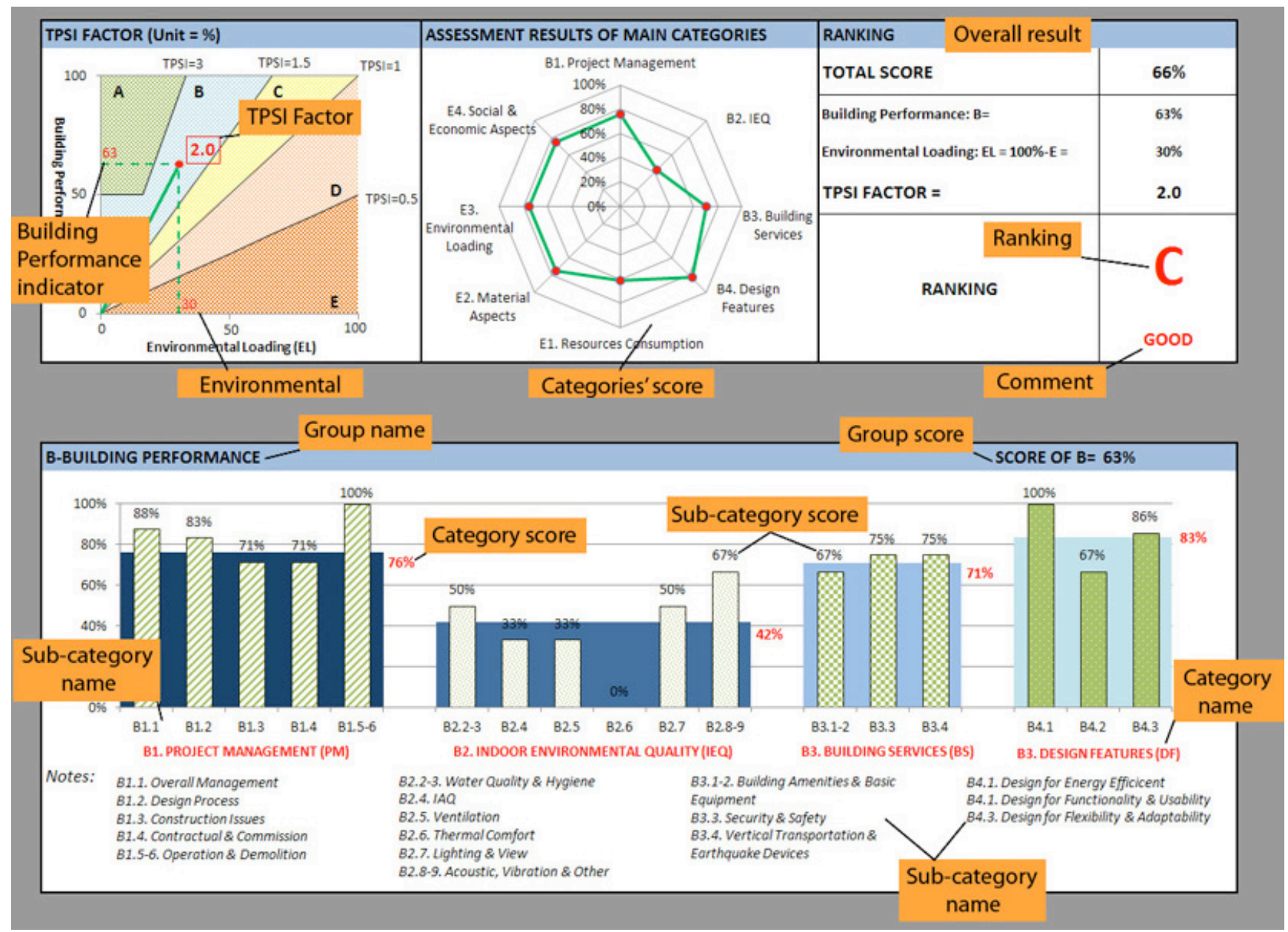

TPSI was thoroughly reviewed during the Interview Process by a criteria system of nine categories (see Table 5). The Interview Process produced a reliable comparison between TPSI and other well-established existing rating systems (i.e., BREEAM, LEED, CASBEE, etc.) when being used in the case studies (tall-building projects).

Table 5. Points achieved by rating systems as a result of the Interview Process.

\begin{tabular}{|c|c|c|c|c|c|c|c|c|}
\hline Title & TPSI & BREEAM & LEED & CASBEE & HK-BEAM & LOTUS & Green Mark & Green Star \\
\hline Availability (/10) & 8 & 9 & 9 & 7 & 8 & 8 & 7 & 7 \\
\hline Methodology (/15) & 12 & 11 & 11 & 12 & 10 & 10 & 11 & 11 \\
\hline Applicability (/20) & 17 & 15 & 15 & 14 & 13 & 11 & 12 & 12 \\
\hline Data Collecting (/8) & 6 & 5 & 7 & 5 & 6 & 6 & 6 & 6 \\
\hline Accuracy (/12) & 10 & 10 & 10 & 11 & 9 & 8 & 8 & 8 \\
\hline User-friendliness (/5) & 5 & 4 & 5 & 3 & 4 & 4 & 4 & 5 \\
\hline Results Presentation (/8) & 8 & 6 & 7 & 7 & 6 & 6 & 6 & 6 \\
\hline Standard Level (/10) & 8 & 8 & 8 & 8 & 8 & 7 & 7 & 7 \\
\hline $\begin{array}{l}\text { Performance } \\
\text { Improvement (/12) }\end{array}$ & 11 & 9 & 8 & 7 & 7 & 6 & 8 & 7 \\
\hline Total (/100) & 85 & 77 & 80 & 74 & 72 & 66 & 69 & 69 \\
\hline
\end{tabular}


Based on the opinions of the participants (Table 5), TPSI's performance in the case studies was rated highest ( 85 points). This result is considered to be reliable considering the class and credibility of the interviewees as well as the number of case studies. The "Applicability" of TPSI was very well appreciated (scored 17/20 points compared to 15 points of both BREEAM and LEED), which proved the suitability and effectiveness of the assessment criteria system. Its "Methodology" point was also higher than that of BREEAM and LEED (12/15 compared to 11/15), which means the assessment process functioned smoothly. The design of TPSI Calculator earned it the highest score in the "Results Presentations" criterion (8/8). Most importantly, tall-building projects that utilized TPSI had improved their sustainability aspects more than all other rating systems, expressed by the "Performance Improvement" point of 11/12, compared to 9/12, 8/12 and 7/12 of BREEAM, LEED and CASBEE respectively.

The Interview Process also revealed TPSI's drawbacks. While TPSI's “Availability” can only be improved after it becomes available to general users, other features can be enhanced. The "Data Inputting" process, at the moment, is over scored by LEED (6/8 compared to 7/8). This has been foreseen as a limitation of the research, since the human resources are not enough to build up some of assessment mechanisms, resulting in the fact that users have to refer to external standards while working in several TPSI issues. Also, the standard level of TPSI was not rated higher than that of BREEAM and LEED although it was one of the initial goals. This feature has been improved by the modification of TPSI Issues' requirements.

To conclude, the Trial Period indicated TPSI's advantages and disadvantages when being used in reality, which in turn helped in perfecting the rating system. It has successfully confirmed TPSI's values as well as the contributions of the research. Opportunities also arose during this period, which afforded further development of the research and extra validation of TPSI rating system.

\subsection{The KTA Proof of Concept Funded TPSI Project}

In March 2011, the research received a $£$ 50,000 EPSRC (the Engineering and Physical Sciences Research Council of the UK) funding from the University of Sheffield's Knowledge Transfer Account (KTA) to develop TPSI further into a commercial online rating tool. A KTA Proof of Concept project was established, which was named "TPSI Project", and is now under development.

The core of the project is the development of TPSI into a Web-based Design/Rating Tool (under the new name- “GreenLight"). The online tool will allow users to:

- Log in and register their high-rise projects;

- Use the online system to assess the sustainability of their projects;

- Use the online system as a design tool or a checklist to follow up and manage their projects throughout its' stages;

- View other rated projects, compare them with their own projects, learn from the others;

- Communicate with other users;

The online tool would be a huge library of tall-building projects. The system would not simply be a rating tool anymore. It will collect all information about a project when it is registered (design, technical information, sustainable strategies, etc.) and make them valuable to other users. 
The second stage is to develop a social-network for individuals and organizations that work in the Built Environment worldwide, named "Sustainable Network". The network will create an online community, an all-in-one stop for anyone involved in the Built Environment. Users will have access to an open and interactive community filled with opportunities. The network will also be equipped with interactive design and management applications. A free Projects Library will also be opened to the public where users can get information about Sustainable Projects worldwide. Users themselves will help in developing this library.

TPSI and other third-party applications will be available on this network, making it the perfect platform to promote and publicize the TPSI rating scheme. This is what has been missing from other rating schemes, and what will make this project unique, apart from the tool itself. Figures 7-10 show some screenshots of the GreenLight online tool and the Sustainable Network. Both the tool and the network will be available at: http://www.sustainable-network.org.

Figure 7. GreenLight Tool-Screenshot.

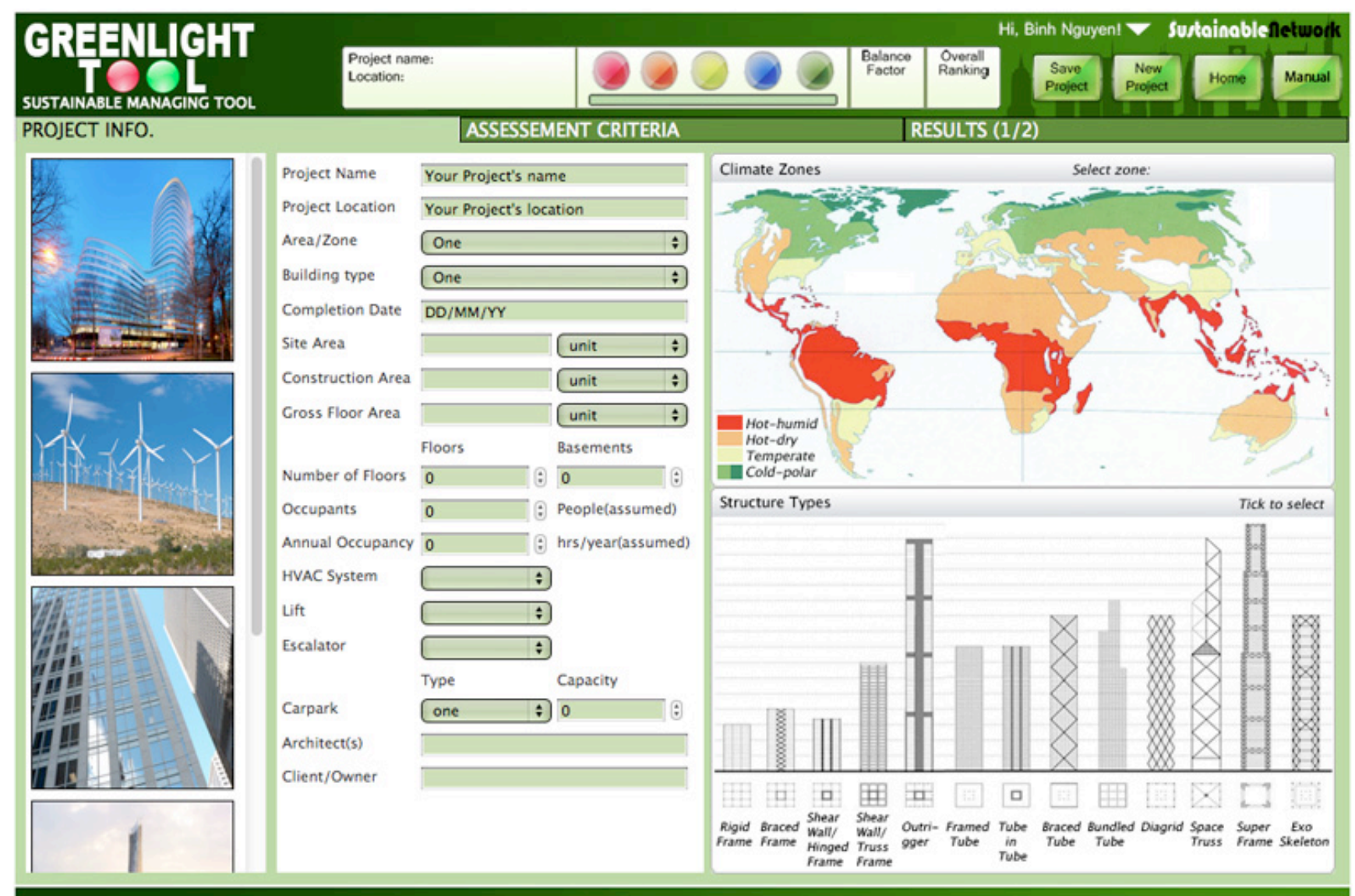


Figure 8. GreenLight Tool—Sample building assessment.

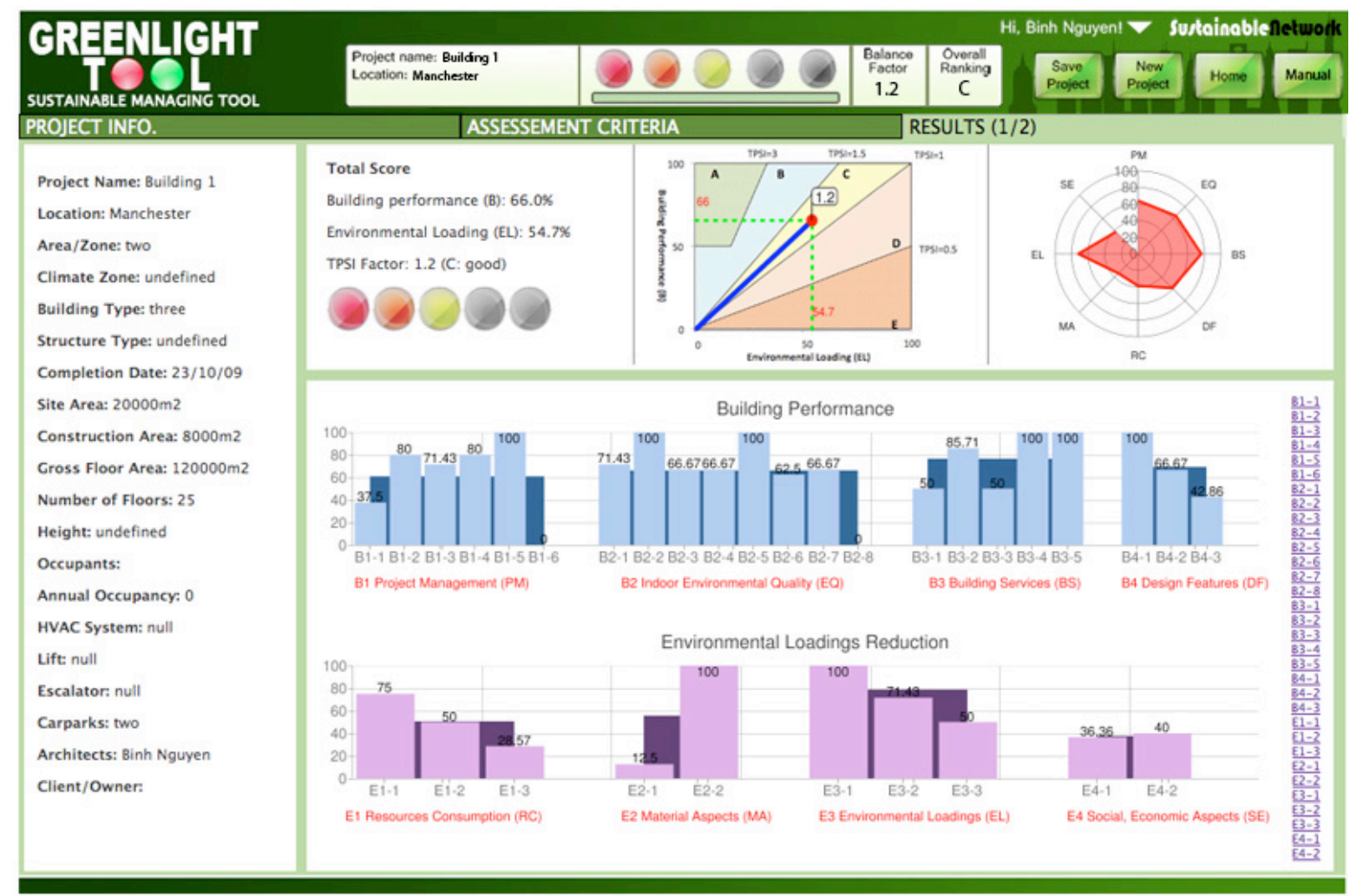

Figure 9. Sustainable Network—-screenshot.

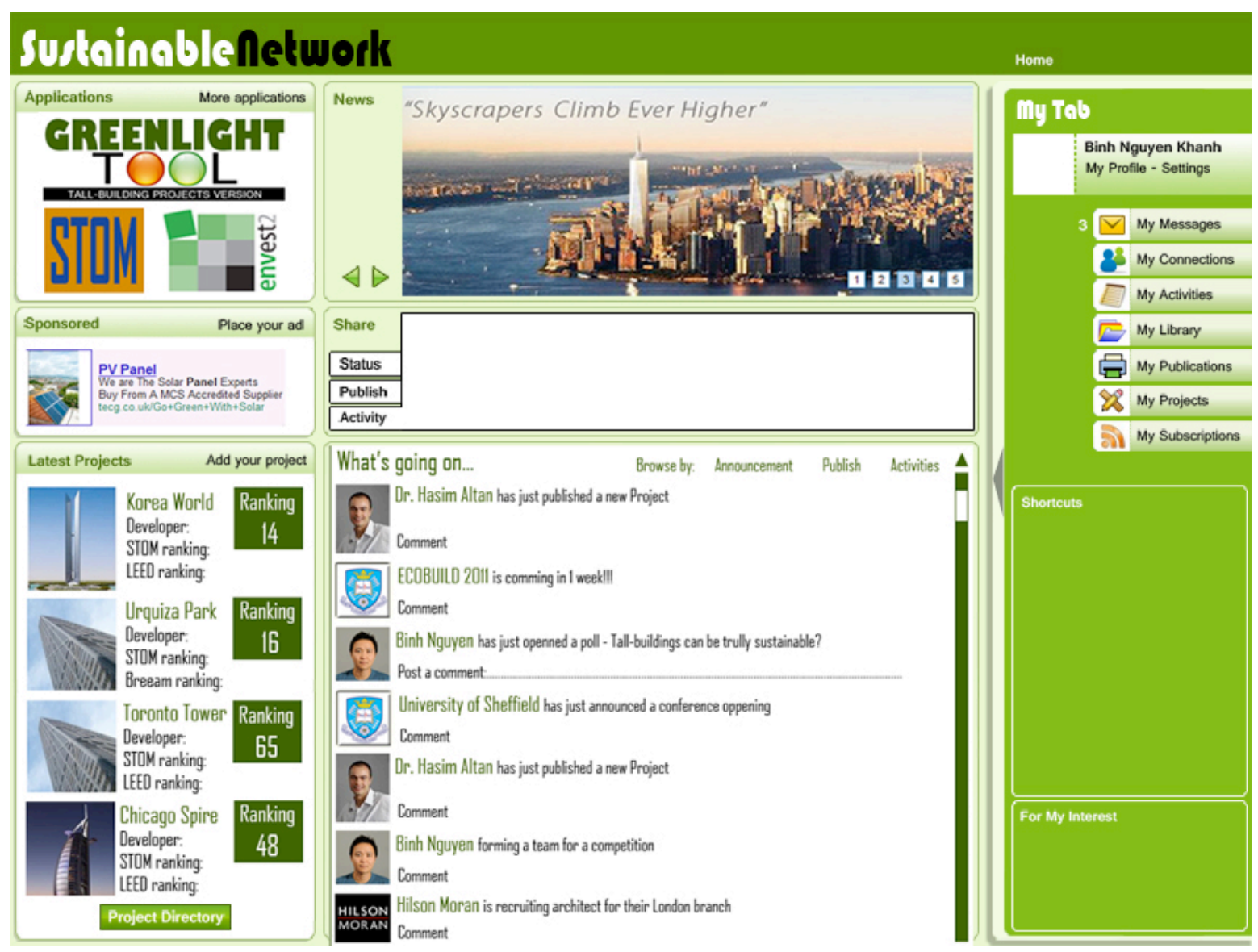


Figure 10. Sustainable Network-Project Directory.

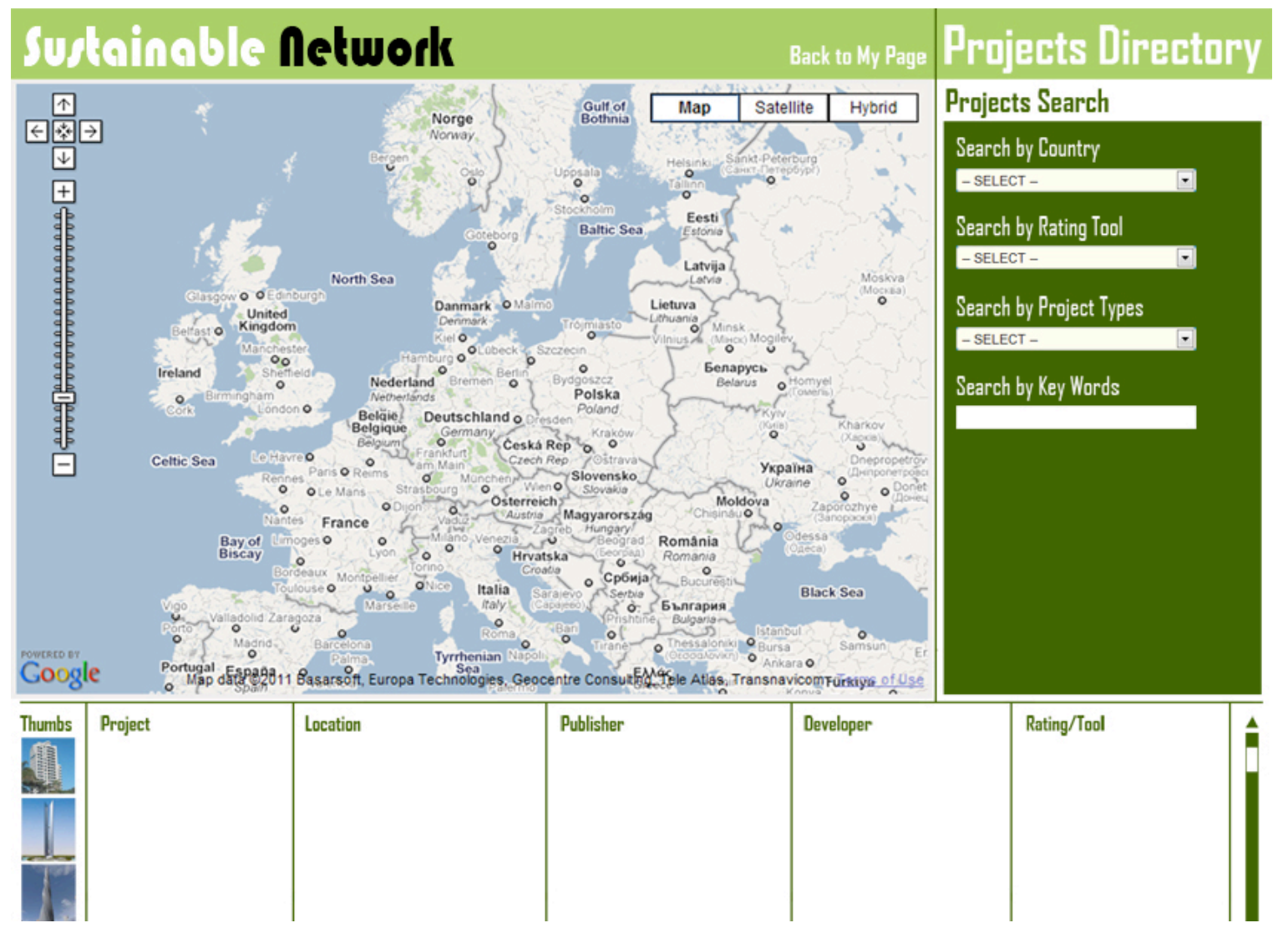

\section{Conclusions}

TPSI Rating System is the outcome of an intensive research into tall-buildings and the assessment of their sustainability. The System not only contributes to the development of sustainability evaluation methods but also raises a new standard for high-performance tall-buildings. This paper summarizes the main features and advantages of TPSI, which proved to be effective in reality. The creation of TPSI has been appraised positively by multiple parties. Its values and advantages have also been validated in many tall-building projects both inside and outside of the UK. With the development of this online tool and the Sustainable Network, it is believed that TPSI will offer remarkable contributions to the Built Environment.

\section{Acknowledgments}

The authors would like to acknowledge the support of the University of Sheffield (UK); School of Architecture for providing the Christopher Jones Studentship and the KTA Proof of Concept Fund. In particular, Building Environments Analysis Unit (BEAU) research centre for providing suitable grounds for such an important project to take place (www.beau-research.co.uk). Other experts also participated during the market research phase, namely Professor Lorna Walker of Walker Consulting Ltd and Pascale Scheurer of Surface to Air Architects. Further support was also provided by Vietnamese Ministry of Construction and Vietnam Green Building Council during the trial period of TPSI Tool. 


\section{References}

1. Fowler, K.M.; Rauch, E.M. Sustainable Building Rating Systems Summary; Pacific Northwest National Laboratory, US Department of Energy: Washington, DC, USA, 2006.

2. Nguyen, B.K. TPSI-Tall-Building Projects Sustainability Indicator. PhD thesis, The University of Sheffield, Sheffield, UK, in press.

3. Cole, R.J. Building environmental assessment methods: Clarifying intentions. Build. Res. Inf. 1999, 27, 230-246.

4. Cole, R.J.; Mitchell, L. Customizing and using GBTool: Two case-study projects. Build. Res. Inf. 1999, 27, 257-275.

5. Khan, F.R. Recent Structural Systems in Steel for High-Rise Buildings. In Proceedings of the British Constructional Steelwork Association Conference on Steel in Architecture, London, UK, 24-26 November 1969.

6. Ali, M.M.; Moon, K.S. Structural developments in tall buildings: Current trends and future prospects. Archit. Sci. Rev. 2007, 50, 205-223.

7. Nguyen, B.K.; Altan, H. TPSI-Tall-Building Projects Sustainability Indicator. In Proceedings of 2011 International Conference of Green Buildings and Sustainable Cities-Procedia Engineering, Bologna, Italy, September 2011; Volume 21, pp. 387-394.

8. Nguyen, B.K.; Altan, H. Comparative Review of Five Sustainability rating systems. In Proceedings of the 2011 International Conference of Green Buildings and Sustainable Cities-Procedia Engineering, Bologna, Italy, September 2011; Volume 21, pp. 376-386.

9. Nguyen, B.K.; Altan, H. Strategies to Reduce Lateral Forces on High-rise Buildings that Use Diagrid Structural System. In Proceedings of the 2011 World Congress on Engineering and Technology-IEEE Press, Shanghai, China, November 2011; Volume 5, pp. 795-798.

10. Nguyen, B.K. Assemble high-rise housing - A solution to Vietnam's housing issues [in Vietnamese]. Archit. J. Vietnam Archit. Assoc. 2009, 167, 27-32.

11. Beetstra, F. Beyond LCA: Building Related Environmental Decisions. In Proceedings of the CIB TG8 2nd International Conference on Buildings and the Environment, Paris, France, June 1997; Volume 2, pp. 565-573.

12. Bordass, W.; Leaman, A. Future buildings and their services. Build. Res. Inf. 1997, 25, 3-16.

13. Bose, R.K. Energy Efficient Cities: Assessment Tools and Benchmarking Practices; World Bank Publications: Washington, DC, USA, 2010.

14. Campbell, E. Assessment of Tools for Rating the Performance of Existing Buildings: A Report on the Options; GVRD: Vancouver, BC, Canada, 2006.

15. Campbell, N.S.; Stankovic, S. Wind Energy for the built Environment; Economic Development Office, Corporation of London: London, UK, 2001.

16. Cole, R.J. Charting the future: Emerging trends in building environmental assessment methods. Build. Res. Inf. 1998, 26, 3-16.

17. Cole, R.J.; Larsson, N. Preliminary Assessment of the GBC Assessment Process. In Proceedings of Green Building Challenge '98, Vancouver, Canada, October 1998; Volume 2, pp. 251-267.

18. Elkington, J. Cannibals with Forks: The Triple Bottom Line of 21st Century Business; New Society Publishers: Vancouver, BC, Canada, 1998. 
19. Fenner, R.A.; Ryce, T. A Comparative Analysis of Two Building Rating Systems-Part 1: Evaluation. In Proceedings of the Institution of Civil Engineers, Engineering Sustainability, New Orleans, USA, March 2008; Volume 161, pp. 55-63.

20. Reed, R.; Bilos, A.; Wilkinson, S.; Shulte, K.W. International comparison of sustainable rating tools. J. Sustain. Real Estate 2009, 1, 1-22.

21. Altan, H. Sustainability Design vs. Energy Performance. In Proceedings of the Oxford Conference 2008: A Re-Evaluation of Education in Architecture, Oxford, UK, July 2008; pp. 177-182.

(C) 2012 by the authors; licensee MDPI, Basel, Switzerland. This article is an open access article distributed under the terms and conditions of the Creative Commons Attribution license (http://creativecommons.org/licenses/by/3.0/). 